\title{
microFLOQ® Direct: a helpful tool for the coronavirus SARS-CoV-2 rapid detection without RNA purification
}

\section{Mathilde Recipon}

CY Cergy Paris University, Equipe de Recherche sur les Relations Matrice Extracellulaire-Cellule (ERRMECE, Mec'uP group, rue Descartes 95000 Neuville-sur-Oise - France

\section{Amaury Pussiau}

Institut de Recherche Criminelle de la Gendarmerie Nationale (IRCGN, 5 Boulevard de I'Hautil, 95000 Cergy - France

\section{Sébastien Follot}

Institut de Recherche Criminelle de la Gendarmerie Nationale (IRCGN, 5 Boulevard de l'Hautil, 95000

Cergy - France

\section{Noussair Latifa}

AP-HP, GHU Paris-Saclay, Hôpital Raymond Poincaré, Garches, France

Jean-Louis Herrmann

AP-HP, GHU Paris-Saclay, Hôpital Raymond Poincaré, Garches, France https://orcid.org/0000-0003-

2347-6418

\section{Martin Rottman}

AP-HP, GHU Paris-Saclay, Hôpital Raymond Poincaré, Garches, France https://orcid.org/0000-00015953-3344

\section{Olivier Gallet}

CY Cergy Paris University, Equipe de Recherche sur les Relations Matrice Extracellulaire-Cellule (ERRMECE, Mec'uP group, rue Descartes 95000 Neuville-sur-Oise - France https://orcid.org/0000-00033731-7311

\section{Sabrina Kellouche}

CY Cergy Paris University, Equipe de Recherche sur les Relations Matrice Extracellulaire-Cellule (ERRMECE, Mec'uP group, rue Descartes 95000 Neuville-sur-Oise - France https://orcid.org/0000-00018444-575X

\section{Johanne Leroy-Dudal}

CY Cergy Paris University, Equipe de Recherche sur les Relations Matrice Extracellulaire-Cellule (ERRMECE, Mec'uP group, rue Descartes 95000 Neuville-sur-Oise - France https://orcid.org/0000-00023002-7381

\section{Georges Pierrini}


Groupement de gendarmerie départementale Quartier Gendarme Dupré, 43 rue du Maréchal Leclerc, 28110 Luce - France

\section{Franck Marescal}

Institut de Recherche Criminelle de la Gendarmerie Nationale (IRCGN, 5 Boulevard de I'Hautil, 95000 Cergy - France

\section{Patrick Touron}

Pôle Judiciaire de la Gendarmerie Nationale (PJGN), 5 Boulevard de l'Hautil, 95000 Cergy - France

\section{Sylvain Hubac}

Institut de Recherche Criminelle de la Gendarmerie Nationale (IRCGN, 5 Boulevard de I'Hautil, 95000 Cergy - France https://orcid.org/0000-0001-7343-5660

\section{Christian Siatka ( $\triangle$ christian.siatka@unimes.fr )}

Nîmes University, CHROME EA 7352, 7 Place Gabriel Péri, 30000 Nîmes - France https://orcid.org/0000-0001-8619-3672

\section{Research Article}

Keywords: COVID-19, molecular diagnosis, Real Time PCR, genetic analysis, outbreak, screening

Posted Date: September 2nd, 2020

DOI: https://doi.org/10.21203/rs.3.rs-70369/v1

License: (c) (i) This work is licensed under a Creative Commons Attribution 4.0 International License. Read Full License

Version of Record: A version of this preprint was published at International Journal of Applied Biology and Pharmaceutical Technology on January 1st, 2022. See the published version at https://doi.org/10.26502/ijabpt.202115. 


\section{Abstract}

In the context of SARS-Cov-2 virus disease (COVID-19) pandemic, molecular diagnostic tools were rapidly developed as there are fundamental for a rapid detection of infected people. In this context, and in order to optimize the manipulations and reduce the time to get results, we report the successful use of a sampling tool for COVID-19 diagnosis named microFLOQ® Direct (MFD). Hundred upper respiratory specimens sampled from patients with potential COVID-19 were evaluated using MFD, and results were compared to the results obtained by standard sampling procedure using dry swabs and physiologic serum as the transport medium. MFD results compared to results issued from the classic RNA purification and amplification steps from transport medium showed that MFD can be directly used for RTPCR analysis without the preliminary inactivation and extraction steps. So, MFD could limit handling errors compared to the different treatment steps with dry swabs and transport medium. It therefore limits the risk of contamination, simplify the analytical process and enables to get results in less than 2 hours. We also show that the MFD kit is operational as a screening tool in the field of molecular detection of viral and bacterial diseases during an outbreak and then it can be used for public health or agroveterinary purposes.

\section{Introduction}

\section{Context}

Since the March 24, 2020, French public authorities as well as the whole world state a health crisis caused by a novel Severe Acute Respiratory Syndrome Coronavirus 2 (SARS-CoV2) named COVID-19, and described for the first time in December 2019 in China [1]. This global health crisis highlights the need for a mobile diagnostic force at national and international level, with clinical diagnostic laboratories to meet the quality standards for medical biology (ISO15189) [2], to best address the needs.

The French National Gendarmerie, as an interior security forces serving the protection of the French people, has taken the initiative to adapt all their possibilities and, moreover, to adapt the forensic Mobil'DNA laboratory [3] as the mobile COVID19 diagnostic force. The objective is to propose an autonomous mobile biomolecular laboratory for rapid tests at high throughput level for the endemic pathogen COVID-19, in support of local hospitals and health systems, in rural or confined areas.

Backed as a proof of concept to pandemic COVID-19, the proposed scheme could be projected in the future in any type of pandemic in areas involving rapid and autonomous reliable detection such as public health, agro-veterinary, plant health screening. In order to be efficient for this mobile force for microbiological diagnosis, the Forensic research institute of from the Gendarmerie Nationale (IRCGN) combined its expertise in mobile and high-speed analysis of biological samples with the expertise of a French medical microbiology laboratory in the diagnosis of endemic pathogens [3].

In order to optimize the diagnostic work in forensic, IRCGN has patented (WO2016132028A1) an original DNA sampling tool [4], the microFLOQ® Direct swab (MFD) (see additional figure 1a) in order to make 
forensic DNA tests easier, faster and directly on the field [5]. Manufactured by COPAN Company (Italy) and initially developed for forensic DNA analysis for crime scene or disaster victim identification (DVI) context, the MFD swab is a miniaturized version of floq swab that presents a $1 \mathrm{~mm} 2 \mathrm{swab}$ head and a breaking point (see additional figure $1 b$ ) that fit perfectly with microtube or with a 96 well PCR microplate. Flocked fibres to the head of the swab present high affinity for nucleic acids and are embedded by lysing agents which allows direct amplification and DNA analysis from sample collection to a final result in less than two hours. Additionally, the MFD swab subsamples only a minute portion of the biological material $(2 \mu \mathrm{l})$ and preserves the vast majority of the sample for subsequent testing or reanalysis. By these properties MFD swab is a useful and smart device for rapid molecular screening on coronavirus SARSCoV-2. In this article, we described a study carried out on 100 samples in order to make a correlation and show that the RT-PCR analysis of COVID-19 can skip the RNA extraction step by simply using the microFLOQ $®$ Direct to detect SARS-CoV-2.

\section{Material Methods}

\section{The genetic diagnosis of SARS-CoV-2}

The SARS-CoV-2 detection is performed from purified RNA by reverse-transcriptase PCR (RT-PCR) [6-8]. The RT-PCR is performed with the GeneFirst RUO COVID-19 Detection Kit (Towngenefirst ${ }^{\circledR}$; UK) that was validated by the French National Reference Centre for respiratory viruses including flu viruses (Pasteur Institute, Paris, France) following the extraction by the Ademtech extraction kit (Ademtech, Bordeaux, France). GeneFirst RT-PCR allowed detection of two specific targets of COVID-19 (N Gene and ORF1 corresponding to the polymerase gene) and one internal control (GAPDH human target) $[6,9]$. Amplification was performed using Applied ${ }^{\text {TM }} 7500$ Real Time PCR system from ThermoFisher (software v2.3). Three different controls were used to define the base lines and the threshold to be applied to unknown samples. The RNA extraction negative control is composed of nuclease free water. The Internal Quality control (ICQ) is composed of quantified virus RNA from positive patients COVID-19 with a defined Ct. The Ct value expected for this ICQ was defined as between 25 and 27. The Positive control is from the supplier (GeneFirst ${ }^{\circledR}$ RUO COVID-19 Detection kit).

\section{Sample Collection}

One hundred samples were collected from symptomatic and asymptomatic patients, present in different institutions (nursing homes, prisons, barracks, etc.). The samples were collected using nasopharyngeal swabs from Copan ${ }^{\circledR}$ according to the manufacturer's recommendations (14). Samples were processed within 24 hours after collection otherwise stored during at $+4^{\circ} \mathrm{C}$ before being processed. All the samples were processed at the same time firstly with microFLOQ ${ }^{\circledR}$ Direct and secondly with standard RNA purification method. 


\section{Sample processing and sample preparation for amplification and SARS-CoV-2 diagnosis: High-throughput COVID-19 detection by RT PCR}

$250 \mu \mathrm{L}$ from $1000 \mu \mathrm{L}$ of transport medium is used for RNA purification. For swabs with alginate conservative medium such as the Copan, total head was discharged in the lysis buffer. RNA purification was performed by lysis of the clinical sample using chemical agents followed by magnetic beads purification using the viral prep Adem-kit ${ }^{\circledR}$ (Ademtech, France), according to the manufacturer recommendations. The extraction step was processed on a KingFisher Flex 96 (ThermoFisher) allowing 96 purifications in 30 minutes. Interpretation and the generation of reports were carried out using GendLink® software adapted to generate a report on the results of COVID-19 analyses.

\section{Sample Processing Using microFLOQ®Direct Swab}

The MFD cannot be used directly for nasopharyngeal sampling because the tip is too short to reach the nasal cavity, and with a high risk of breaking inside the cavity. Furthermore, the lysis agents embedded on the fibres are also not safe for humans. In this study, MFD swab was used by subsampling the regular nasopharyngeal swab after collection.

For subsampling, the MFD swab was brought into contact with the tip of the swab used for nasopharyngeal sampling 2 seconds by tapping (see additional figure 2). In the absence of a swab in the sample (swab discharged into the transport medium), the MFD swab is brought into contact for 2 seconds with the transport medium present in the cap of the sample tube after shaking the tube (see additional figure 3). MFD was then broken at his breakable point in the well of a 96 well PCR microplate or in a microtube containing $10 \mu \mathrm{l}$ of elution buffer (Nuclease Free water). The elution step occurred during 10 minutes, at room temperature, under stirring at $500 \mathrm{rpm}$. A $5 \mu \mathrm{l}$ of elution buffer was taken and added to $15 \mu$ of RT-PCR mix to then be amplified.

\section{Interpretation of results}

There are 3 categories of results:

- Patients infected by the COVID-19 (COVID +): Among COVID + population we distinguish full and dissociated. A full category means that a CT value under 40 CT (Cycle Threshold) is obtained for both NGene and ORF1 ab specific targets of COVID whereas a dissociated category means that a CT value is obtained for only one specific target of COVID (NGene or ORF1 ab. The maximum value of 40 CT fixed by the manufacturer to declare positive results;

- Patients non-infected by COVID-19 (COVID -): no CT value (No CT) is observed for both NGene and ORF1 ab specific targets of COVID; 
- Patients undetermined (COVID undetermined): impossible to provide a diagnostic due to the nondetection of Human Target.

\section{Results}

\section{Results obtained with the regular RNA purification method}

The results obtained with the regular RNA purification method allowed to declare 42 patients infected by the COVID-19 (COVID +), 57 patients non-infected by COVID-19 (COVID -) and 1 patient undetermined (COVID undetermined) (table 1).

\section{Results obtained with the microFLOQ® Direct method}

The results obtained with the microFLOQ $®$ Direct method allowed to declare 18 patients infected by the COVID-19 (COVID +) and 82 patients non-infected by COVID-19 (COVID -) (table 1).

\section{Concordance study}

For each COVID +, COVID - and COVID undetermined populations and categories, we compared the results obtained with conventional RNA purification protocol to those obtained from microFLOQ ${ }^{\circledR}$ Direct protocol in order to determine the concordance or discordance between the two methods.

Concerning patients declared non-infected by COVID-19 using regular method, a complete concordance is obtained for all the samples $(n=57)$.

Concerning patients declared infected by COVID-19, a complete concordance is obtained for the full category $(n=14)$ where a CT median value for RNA purification method is under or equal to 28 (table 1 ) with minimum value of 17 and a maximum value around 38 . For this full category, we observed a difference of +2 and +4 CT (CT median) with microFLOQ ${ }^{\circledR}$ Direct method compared to RNA purification method (figure 1). For the dissociated category, a complete concordance is observed for 4 samples where a CT median value and a minimum value are 38 (figure 1). For this category, we observed an offset to -3 CT (median value) with microFLOQ ${ }^{\circledR}$ Direct method compared to RNA purification method. On the other hand, at similar CT median value to $36 \mathrm{CT}$ and more, we observed a complete discordance between microFLOQ® Direct and RNA purification protocols for 24 samples.

Concerning the CT for human targets, we observed a constant value for all conditions for both microFLOQ $®$ Direct and RNA purification method with an offset between +4 to +6 for microFLOQ ${ }^{\circledR}$ Direct protocol. This result demonstrates that human target control detection is not correlated to the specific targets of COVID-19. 
We can underline that for one sample Human Target is not detected using RNA purification method suggesting inhibition of RT PCR reaction due to residual inhibitors after purification, while a human CT value to 26 cycles were obtained with microFLOQ® Direct. These results show that use of microFLOQ ${ }^{\circledR}$ Direct reduce the volume of samples collected what can limit the sensibility of the method but, on the other hand, limit the impact of residual RT PCR inhibitors after RNA purification.

Table 1: Cycles Threshold (CT) values obtained using microFLOQ® Direct (MF) compared to RNA purification protocol from 100 samples.

\begin{tabular}{|c|c|c|c|c|c|c|c|c|c|c|c|c|c|c|}
\hline & \multicolumn{7}{|c|}{$\begin{array}{c}\text { COVID + } \\
\text { Concordance } \\
\text { [full, n=14] }\end{array}$} & \multicolumn{7}{|c|}{$\begin{array}{c}\text { COVID + } \\
\text { Concordance } \\
\text { [dissociated, } n=4 \text { ] }\end{array}$} \\
\hline & \multicolumn{3}{|c|}{ microfLOQ DireCT } & \multicolumn{3}{|c|}{ RNA purification } & \multirow{2}{*}{$\begin{array}{l}\text { Delta CT } \\
\text { Mediane }\end{array}$} & \multicolumn{3}{|c|}{ microf LOQ DireCT } & \multicolumn{3}{|c|}{ RNA purification } & \multirow{2}{*}{$\begin{array}{l}\text { Delta } \mathrm{CT}^{2} \\
\text { Mediane }\end{array}$} \\
\hline & $\begin{array}{l}\mathrm{CT} \\
\mathrm{Mn}\end{array}$ & $\begin{array}{l}\mathrm{CT}^{*} \\
\text { Max }\end{array}$ & $\begin{array}{c}\mathrm{CT}^{*} \\
\text { Mediane }\end{array}$ & $\begin{array}{l}\mathrm{CT} \\
\text { Min }\end{array}$ & $\begin{array}{l}\mathrm{CT}^{*} \\
\text { Max }\end{array}$ & $\begin{array}{c}\mathrm{CT}^{*} \\
\text { Mediane }\end{array}$ & & $\begin{array}{l}\mathrm{CT}^{\mathrm{x}} \\
\mathrm{Min}\end{array}$ & $\begin{array}{l}\mathrm{CT}^{x} \\
\mathrm{Max}\end{array}$ & $\begin{array}{c}\mathrm{CT}^{*} \\
\text { Mediane }\end{array}$ & $\begin{array}{l}\mathrm{CT} \\
\text { Min }\end{array}$ & $\begin{array}{l}\mathrm{CT}^{*} \\
\text { Max }\end{array}$ & $\begin{array}{c}\mathrm{CT}^{*} \\
\text { Mediane }\end{array}$ & \\
\hline Human & 22 & 32 & 27 & 19 & 27 & 21 & 6 & 22 & 32 & 26 & 20 & 27 & 22 & 5 \\
\hline NGene & 24 & 39 & 31 & 17 & 38 & 27 & 4 & 30 & 38 & 35 & 38 & 38 & 38 & -3 \\
\hline ORF1 ab & 23 & 41 & 30 & 17 & 38 & 28 & 2 & 32 & 39 & 35 & 38 & 38 & 38 & 3 \\
\hline
\end{tabular}

\begin{tabular}{|c|c|c|c|c|c|c|c|c|c|c|c|c|c|c|}
\hline & \multicolumn{7}{|c|}{$\begin{array}{c}\text { COVID + } \\
\text { Discordance } \\
\text { [dissociated, } n=8 \text { ] }\end{array}$} & \multicolumn{7}{|c|}{$\begin{array}{l}\text { COVID + } \\
\text { Discordance } \\
\text { [full, } n=16]\end{array}$} \\
\hline & \multicolumn{3}{|c|}{ microFLOQ DireCT ${ }^{*}$} & \multicolumn{3}{|c|}{ RNA purification } & \multirow{2}{*}{$\begin{array}{l}\text { Deita CT } \\
\text { Mediane }\end{array}$} & \multicolumn{3}{|c|}{ microf LOQ DireCT* ${ }^{\star}$} & \multicolumn{3}{|c|}{ RNA purification } & \multirow{2}{*}{$\begin{array}{l}\text { Delta CT } \\
\text { Mediane }\end{array}$} \\
\hline & $\begin{array}{l}\mathrm{CT}^{x} \\
\mathrm{Mn}\end{array}$ & $\begin{array}{l}\mathrm{CT}^{*} \\
\text { Max }\end{array}$ & $\begin{array}{c}\mathrm{CT}^{*} \\
\text { Mediane }\end{array}$ & $\begin{array}{l}\mathrm{CT}^{*} \\
\text { Min }\end{array}$ & $\begin{array}{l}\mathrm{CT}^{x} \\
\text { Max }\end{array}$ & $\begin{array}{c}\mathrm{CT}^{x} \\
\text { Mediane }\end{array}$ & & $\begin{array}{l}\mathrm{CT}^{\mathrm{x}} \\
\text { Min }\end{array}$ & $\begin{array}{l}\mathrm{CT}^{\mathrm{x}} \\
\mathrm{Max}\end{array}$ & $\begin{array}{c}\mathrm{CT}^{*} \\
\text { Mediane }\end{array}$ & $\begin{array}{c}\mathrm{CT}^{*} \\
\text { Min }\end{array}$ & $\begin{array}{l}\mathrm{CT}^{x} \\
\operatorname{Max}\end{array}$ & $\begin{array}{c}\mathrm{CT}^{*} \\
\text { Mediane }\end{array}$ & \\
\hline Human & 23 & 28 & 26 & 20 & 23 & 21 & 4 & 23 & 29 & 27 & 19 & 24 & 21 & 6 \\
\hline NGene & No CT & $\mathrm{NoCT}^{*}$ & No CT ${ }^{*}$ & 37 & 38 & 37 & & NoCT ${ }^{*}$ & No C $T^{*}$ & No $\mathrm{CT}^{*}$ & 32 & 39 & 36 & \\
\hline ORF1 ab & No CT & No C T & \begin{tabular}{|l} 
No $\mathrm{CT}^{2}$ \\
\end{tabular} & 37 & 39 & 38 & & No C $T^{*}$ & No $\mathrm{CT}^{*}$ & NoCT ${ }^{*}$ & 32 & 39 & 36 & \\
\hline
\end{tabular}

\begin{tabular}{|c|c|c|c|c|c|c|c|c|c|c|c|c|c|c|}
\hline & \multicolumn{7}{|c|}{$\begin{array}{c}\text { COVID - } \\
\text { Concordance } \\
\left.\text { [full No } \mathrm{CT}^{\star}, n=52\right]\end{array}$} & \multicolumn{7}{|c|}{$\begin{array}{c}\text { COVD - } \\
\text { Concordance } \\
{\left[\mathrm{CT}^{\star} \text { value } \geq 40, n=5\right]}\end{array}$} \\
\hline & \multicolumn{3}{|c|}{ microFLOQ DireCT } & \multicolumn{3}{|c|}{ RNA purification } & \multirow{2}{*}{$\begin{array}{l}\text { Deita CT } \\
\text { Mediane }\end{array}$} & \multicolumn{3}{|c|}{ microf LOQ DireCT* } & \multicolumn{3}{|c|}{ RNA purification } & \multirow{2}{*}{$\begin{array}{l}\text { Delta CT } \\
\text { Mediane }\end{array}$} \\
\hline & $\begin{array}{l}\mathrm{CT}^{*} \\
\mathrm{Mn}\end{array}$ & $\begin{array}{l}\mathrm{CT}^{*} \\
\text { Max }\end{array}$ & $\begin{array}{c}\mathrm{CT}^{*} \\
\text { Mediane }\end{array}$ & $\begin{array}{l}\mathrm{CT}^{*} \\
\text { Min }\end{array}$ & $\begin{array}{l}\mathrm{CT}^{x} \\
\text { Max }\end{array}$ & $\begin{array}{c}\mathrm{CT}^{*} \\
\text { Mediane }\end{array}$ & & $\begin{array}{l}\mathrm{CT}^{\mathrm{T}} \\
\text { Min }\end{array}$ & $\begin{array}{l}\mathrm{CT}^{2} \\
\text { Max }\end{array}$ & $\begin{array}{c}\mathrm{CT}^{*} \\
\text { Mediane }\end{array}$ & $\begin{array}{l}\mathrm{CT}^{2} \\
\text { Min }\end{array}$ & $\begin{array}{l}\mathrm{CT}^{*} \\
\operatorname{Max}\end{array}$ & $\begin{array}{c}\mathrm{CT}^{*} \\
\text { Mediane }\end{array}$ & \\
\hline Human & 23 & 32 & 26 & 16 & 26 & 22 & 4 & 24 & 27 & 26 & 19 & 22 & 20 & 5 \\
\hline NGene & No CT & $\mathrm{NoCT}^{2}$ & No CT* & No CT" & $\mathrm{NoCT}^{*}$ & No CT ${ }^{*}$ & & NoCT ${ }^{*}$ & No CTㄹ & NoCT ${ }^{*}$ & 40 & 40 & 40 & \\
\hline ORF1 ab & No CT: & $\mathrm{NoCT}^{2}$ & No CT ${ }^{*}$ & No CT" & $\mathrm{NoCT}^{*}$ & No CT ${ }^{*}$ & & 40 & 40 & 40 & 40 & 42 & 41 & -1 \\
\hline
\end{tabular}

\begin{tabular}{|c|c|c|}
\hline & \multicolumn{2}{|c|}{$\begin{array}{l}\text { COVID undetermined } \\
\text { Discordance } \\
{[n=1]}\end{array}$} \\
\hline & microFLOQ DireCT & RNA purification \\
\hline & $\mathrm{CT}^{*}$ & $\mathrm{CT}^{*}$ \\
\hline Human & 26 & $\mathrm{NoCT}^{*}$ \\
\hline NGene & No $\mathrm{CT}^{*}$ & $\mathrm{NOCT}^{*}$ \\
\hline ORF1 ab & No $\mathrm{CT}^{2}$ & $\mathrm{NoCT}^{*}$ \\
\hline
\end{tabular}

(") value rounded to unit

COVID +: patients diagnosed infected by COVID-19; COVID -: patients diagnosed non-infected by COVID-19; COVID undetermined: impossible to provide a diagnostic due to the non-detection of Human Target.

Concordance: concordance between MF results and RNA purification results. A concordance is considered if a CT value or not CT value ( $(\mathrm{No} C T)$ is obtained for both MF and RNA purification conditions; Discordance: discordance between MF results and RNA purification results. A 
discordance is considered if a CT value or not CT value ((No CT) is obtained for MF or RNA purification conditions.

Full: CT value obtained for the two specific targets of COVID-19 (Ngene and ORF 1 ab); dissociated: CT value obtained for only on specific targets of COVID-19 (Ngene or ORF1 ab).

CT Min: CT value minimum obtained; CT Max, CT value maximum obtained; CT Median: CT value median obtained; Delta CT median: difference of CT values between CT median obtained for MF protocol and CT median obtained for RNA purification protocol; $n=$ number of samples processed.

This comparative study demonstrates that microFLOQ® Direct swab method provides $100 \%$ of concordant results compared to regular RNA purification method for patients non-infected by the COVID19 and $43 \%$ of concordant results for patients declared infected by COVID-19 This difference of diagnosis is due to an offsets +6 to +7 CT if we consider minimum CT value and +2 to +4 CT for a median value when using microFLOQ ${ }^{\circledR}$ Direct protocol. This can be explained by a starting dilution factor which is not the same. The dilution factor for RNA purification protocol is 1:48 $(250 \mu \mathrm{l}$ from $1000 \mu \mathrm{l}$ of transport medium and $5 \mu \mathrm{l}$ from $60 \mu$ of eluted RNA) while the dilution factor for microFLOQ® Direct protocol is 1:1000 considering that microFLOQ ${ }^{\circledR}$ Direct swab can collect a maximum volume of $2 \mu \mathrm{l}(2 \mu \mathrm{l}$ from $1000 \mu \mathrm{l}$ of transport medium or direct collected from the tip of the nasopharyngeal swab and $5 \mu \mathrm{l}$ to $10 \mu \mathrm{l}$ of elution buffer).

If we consider a maximum CT value of 40 , this offset of +6 to +7 CT is not significant for COVID-19 diagnostic concerning patients for which a CT value under $33 \mathrm{CT}$ could be obtained from RNA purification method. For previous results obtained during internal validation studies of the GeneFirst ${ }^{\circledR}$ RUO COVID-19 Detection kit, we analysed a second time 38 samples were dissociated results were obtained at the first analysed with minimum CT value between 33 to 35, maximum CT value between 40 to 41 and a median CT value at 38 . In $61 \%$ of cases (23 samples/38), a negative result (No CT) for NGene targets we obtained for the second analyse and in $42 \%$ of cases $(16 / 38)$ for ORF1 ab target (data not published yet). These results demonstrate that for a CT value of 35 to 38 and more, the reproducibility of the regular RNA purification method is around $60 \%$. We do not observe this variability for microFLOQ® Direct method suggesting that this protocol could be more robust than the RNA purification method.

\section{Discussion}

The devices and processes for the collection of biological materials favouring a rapid and simplified DNA analysis each respond to a particular problem, but none meets a global need: having the same and the most simplified tool to collect and analyse as quickly as possible DNA and RNA [10].

In addition, the devices must not alter the biological sample in order to authorize additional analyses and must secure the biological material collected to minimize the risk of contamination. They must also be 
compatible with conventional methods, reagents and analytical instruments commonly used in analysis laboratories, particularly compatible with RT-PCR amplification.

Finally, they must be compatible with high throughput processing of samples without the need for robotic sample preparation platforms, have efficiency at least equivalent to that of current devices and if possible reduce costs compared to the cost of a conventional analysis.

The microFLOQ $\circledast$ Direct swab is a device used in the proposed alternative process, easy to use and compatible for high-speed analyses without the need for nucleic acids purification reagent reactions and instrument.

The presentation of these comparative results on 100 samples between the conventional RNA analysis method and the alternative method using microFLOQ ${ }^{\circledR}$ Direct swab shows that microFLOQ ${ }^{\circledR}$ Direct can be used to carry out tests for RT-PCR detection of SARS-CoV-2.

Subsampling immediately with the microFLOQ ${ }^{\circledR}$ Direct swab the regular swab used for the sample collection could be a technical and logistical advantage if we can demonstrate that the lysis agents embedded on the fibres microFLOQ® Direct swab inactivates instantly the virus. In this way, it is therefore no longer compulsory to work in the laboratory under type 2 microbiological safety cab (MSC). The CT shift observed between microFLOQ® Direct swab protocol and regular RNA purification protocol could be mainly explained by putative concentration of virus 200 times more important in the sample process with the regular RNA purification protocol than the microFLOQ® Direct protocol. If we consider a PCR efficiency with $100 \%$ assuming all other factors such as instruments, reagents are equal, an offset of 6-7 CT produced from the same sample collected by two different ways, means that the amount of template collected is $2^{6}(64)$ to $2^{7}(128)$ times lower between the two conditions. This theoretical result is in accordance to the offset of CT observe between microFLOQ® Direct swab and RNA purification protocols.

Furthermore, this offset is not significant for COVID-19 diagnostic concerning patients for which a CT value under 33 CT could be obtained from RNA purification method. In active epidemic phase, this result let's consider using microFLOQ ${ }^{\circledR}$ Direct swab like an innovative strategy for rapid screening test to detect viruses in active epidemic phase like (figure 2). Asymptomatic and symptomatic patients are sampled using regular nasopharyngeal swabs. MicroFLOQ® Direct swab is firstly used directly on the collection site for subsampling the nasopharyngeal swab and processed in a mobile laboratory in order to obtain the results in less than 90 minutes without need of additional RNA purification reagent and instrument compared to 130 minutes using conventional RNA purification method with Ademtech viral prep kit. In case of positive result, the patient could be immediately isolated and protected (chirurgical mask) and the persons in contact with this patient could be immediately identified and sampled. In this case, the nasopharyngeal swab subsampled with microFLOQ® Direct swab could be stored in order to build a biobank of original samples. This approach could be very useful to constitute a cohort of samples that could be used to develop new protocol to detect the virus or and analyse later if necessary to establish 
correlation with clinical symptoms, for example. In case of negative result with microFLOQ® Direct rapid screening, the nasopharyngeal swab is shipped to the laboratory and the conventional RNA purification protocol is done in order to confirm under 24 hours (including the shipment delay) the negative result or declare a positive result.

In order to enhance the quantity of the virus to be analysed without RNA purification, we could propose the use of FTA cards instead of microFLOQ ${ }^{\circledR}$ Direct swab. FTA card is also treated with lysis reagents allowing direct RNA amplification [11]. The benefit to the FTA card is the possibility to perform multiples punching at different diameters in order to enhance the quantity of samples analysed [12]. However, if you need to process a lot of samples, the use of the semi-automatic or automatic puncher with a unique punching head is a putative risk of cross contamination that must be evaluated. To prevent this risk, the best way could be to change the punching head between each sample or clean the punching head that is time consuming, not cost effective and not compatible with high throughput screening. Even if the quantity of samples collected is a limitation for the sensibility of the method, the one shot use of microFLOQ $\circledast$ Direct swab could be the best compromise for rapid screening by preventing the risk of cross contamination during the analytical process.

\section{Conclusion}

On 100 samples, we found that the microFLOQ® Direct swab presents an interesting alternative to conventional nucleic acid purification method to analyse viruses like coronavirus SARS-Cov-2. During an active epidemic phase, microFLOQ ${ }^{\circledR}$ Direct swab could be an innovative strategy for rapid screening test to detect viruses in less than 90 minutes and adopt immediately the measures to stop the propagation of the virus. By consuming an insignificant fraction of the sample, the subsampling method using microFLOQ ${ }^{\circledR}$ Direct swab enables to store the original sample (nasopharyngeal swab or liquid) in order to build a biobank very useful for technical and clinical research. In addition, the use of microFLOQ® Direct swab reduce analysis costs compared to the conventional RNA purification reagents and instruments, reducing the working time and handling steps while ensuring greater protection for the manipulator and offer the possibility to perform the analyse directly to the collection site inside a mobile laboratory.

\section{Compliance With Ethical Standards}

\section{Funding}

Recipon M. is recipient of INEX ANR project GendTrack and project GendSwab from CY Initiative Institute for Advanced Studies

\section{Conflict of interest}

Hubac S. is the owner of the patent of Mobil'DNA and the microFLOQ® Direct swab. 


\section{Ethical approval}

Ethics review is not required under French Law.

\section{Informed consent}

Not applicable.

\section{Acknowledgment}

We are grateful to the Pr Philippe Berta, geneticis at Nîmes University for his excellent expert advice and reviewing, as well as Pr Franck Carreiras for his encouragement and support throughout this project, and also Rémy Agniel for his technical assistance and brilliance in the lab.

\section{References}

1. Li Q, Guan X, Wu P, Wang X, Zhou L, Tong Y, et al. Early Transmission Dynamics in Wuhan, China, of Novel Coronavirus-Infected Pneumonia. N. Engl. J. Med. 2020;382:1199-207. doi: 10.1056/NEJMoa2001316

2. Ho B. Practical Application of ISO 15189 by Accreditation Bodies -: A comparison with ISO/IEC 17025. EJIFCC 2004;15:128-35.

3. Touron P, Siatka C, Pussiau A, Follot S, Fritz T, Petit M, et al. A mobile DNA laboratory for forensic science adapted to coronavirus SARS-CoV-2 diagnosis. Eur. J. Clin. Microbiol. Infect. Dis. 2020 14;doi: 10.1007/s10096-020-03989-3

4. HUBAC S. Device for collecting biological material from a biological trace [Internet]. 201625 [cited 2020 31];doi: https://patents.google.com/patent/WO2016132028A1/en

5. Gaudry E, Dourel L, Conigliaro A, Georget C, Desbrosse X, Hubac S. L'identification de victimes de catastrophe: une approche scientifique pluridisciplinaire. Revue Francophone des Laboratoires [Internet] 20171 [cited 2020 24];2017:41-57. doi:

http://www.sciencedirect.com/science/article/pii/S1773035X17300291doi: 10.1016/S1773035X(17)30029-1

6. Corman VM, Landt O, Kaiser M, Molenkamp R, Meijer A, Chu DKW, et al. Detection of 2019 novel coronavirus (2019-nCoV) by real-time RT-PCR. Euro Surveill. 2020;25. doi: 10.2807/15607917.ES.2020.25.3.2000045

7. Okamaoto K, Shirato K, Nao N, Saito S, Kageyama T, Hasegawa H, et al. An assessment of real-time RT-PCR kits for SARS-CoV-2 detection. Jpn. J. Infect. Dis. 2020 30;doi: 10.7883/yoken.JJID.2020.108

8. Lescure F-X, Bouadma L, Nguyen D, Parisey M, Wicky P-H, Behillil S, et al. Clinical and virological data of the first cases of COVID-19 in Europe: a case series. Lancet Infect Dis 2020;20:697-706. doi: 10.1016/S1473-3099(20)30200-0 
9. Chan JF-W, Yip CC-Y, To KK-W, Tang TH-C, Wong SC-Y, Leung K-H, et al. Improved Molecular Diagnosis of COVID-19 by the Novel, Highly Sensitive and Specific COVID-19-RdRp/Hel Real-Time Reverse Transcription-PCR Assay Validated In Vitro and with Clinical Specimens. J. Clin. Microbiol. 2020;58. doi: 10.1128/JCM.00310-20

10. Ambers A, Wiley R, Novroski N, Budowle B. Direct PCR amplification of DNA from human bloodstains, saliva, and touch samples collected with microFLOQ® swabs. Forensic Sci Int Genet 2018;32:80-7. doi: 10.1016/j.fsigen.2017.10.010

11. Cardona-Ospina JA, Villalba-Miranda MF, Palechor-Ocampo LA, Mancilla LI, Sepúlveda-Arias JC. A systematic review of FTA cards $\AA$ as a tool for viral RNA preservation in fieldwork: Are they safe and effective? Prev. Vet. Med. 2019 15;172:104772. doi: 10.1016/j.prevetmed.2019.104772

12. da Cunha Santos G. FTA Cards for Preservation of Nucleic Acids for Molecular Assays: A Review on the Use of Cytologic/Tissue Samples. Arch. Pathol. Lab. Med. 2018;142:308-12. doi: 10.5858/arpa.2017-0303-RA

\section{Figures}

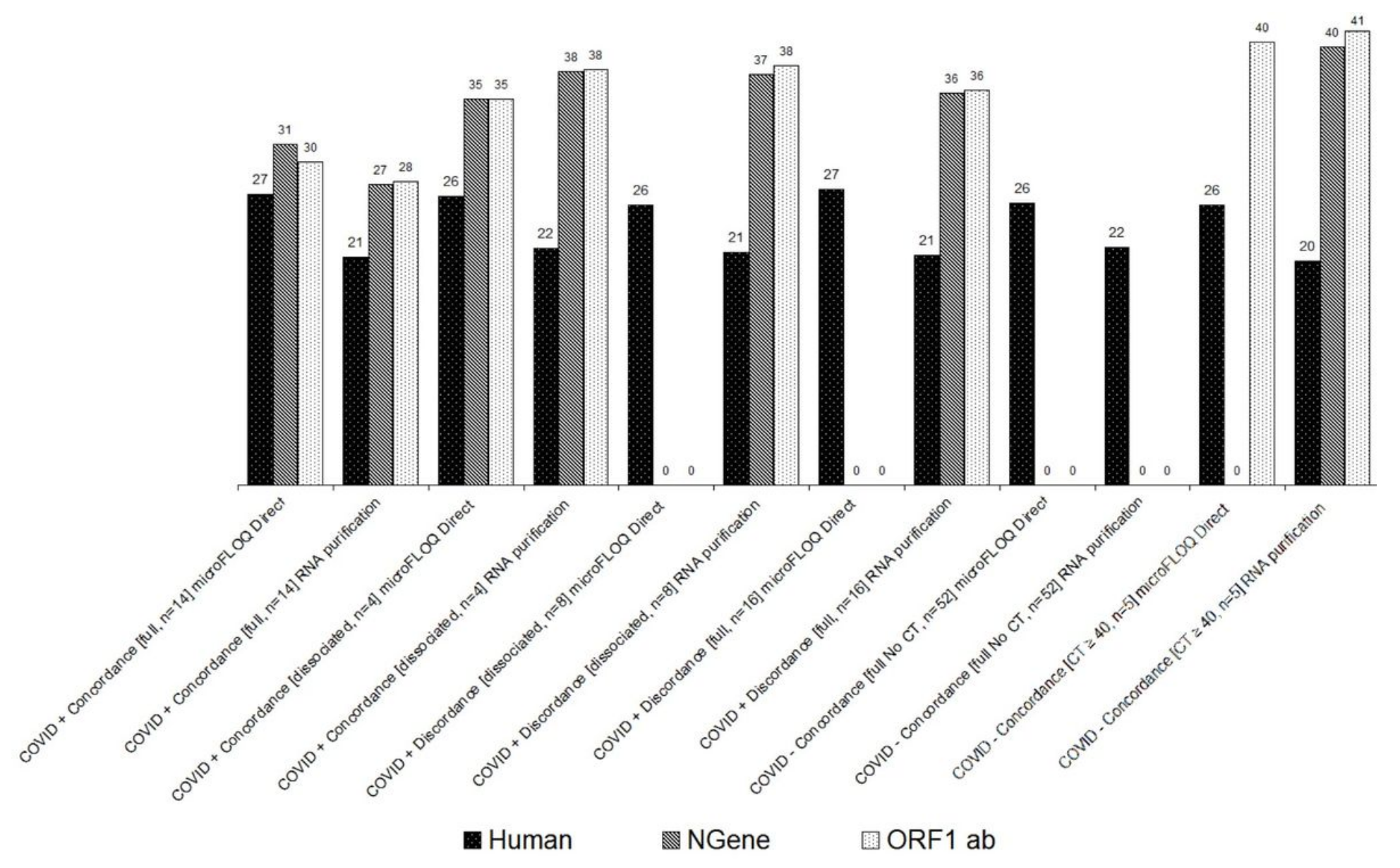

Figure 1 
Graphic representation of Cycles Threshold (CT) median values obtained using microFLOQ® Direct (MF) compared to RNA purification protocol from 100 samples. COVID +: patients diagnosed infected by COVID-19; COVID -: patients diagnosed non-infected by COVID-19; COVID undetermined: impossible to provide a diagnostic due to the non-detection of Human Target. Concordance: concordance between MF results and RNA purification results. A concordance is considered if a CT value or not CT value ((No CT) is obtained for both MF and RNA purification conditions; Discordance: discordance between MF results and RNA purification results. A discordance is considered if a CT value or not CT value ( $(N o C T)$ is obtained for MF or RNA purification conditions. Full: CT value obtained for the two specific targets of COVID-19 (Ngene and ORF $1 \mathrm{ab}$ ); dissociated: CT value obtained for only on specific targets of COVID-19 (Ngene or ORF1 ab).

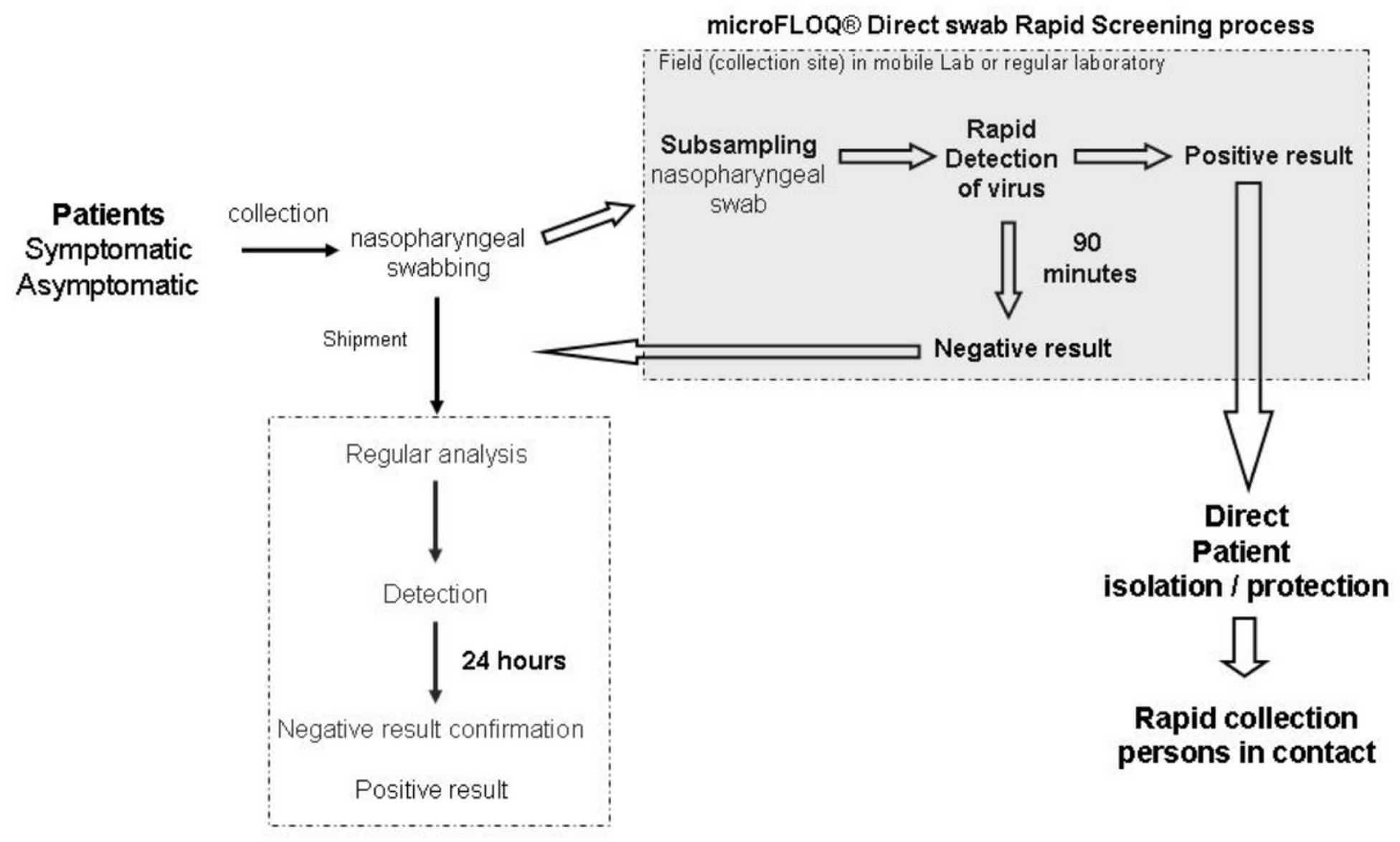

Figure 2

microFLOQ ${ }^{\circledR}$ Direct swab rapid screening process to detect viruses.

\section{Supplementary Files}

This is a list of supplementary files associated with this preprint. Click to download.

- AdditionalFigures.docx 